\title{
GRAVE, Crescenciano. (2019). Walter Benjamin. Una constela- ción crítica de la modernidad. UNAM.
}

OSMAN SERRANO MARTÍNEZ

Cepillar a contrapelo la historia - junto a los autores y temas que trató, reconstruyó y reconfiguró- es el cometido que desde siempre ejecutó Walter Benjamin en su pensamiento crítico; o, si se prefiere, en su crítica literaria. A final de cuentas, el berlinés consideraba que en su tiempo la crítica literaria alemana tenía carencias considerables, e intentó convertirse, según lo revela en cartas a sus amigos - modestia aparte-, en el mejor crítico literario en lengua alemana del siglo que le tocó vivir. Póstumo como Nietzsche o Schopenhauer, el tiempo le daría la razón de sobra: sus agudas críticas sobre Brecht -el interlocutor con quien tuvo serias discrepancias en la recepción del marxismo-, Kafka, Goethe, el Trauerspiel alemán, Baudelaire - su tan apasionado soulmate, de quien tradujo las Tableaux parisiens de Les fleurs du mal, cuya lectura de la traducción sacaría de quicio a un Stefan Zweig reacio-, no son sino la prueba suficiente de lo que acabamos de decir. Detallando este jaloneo que se da entre crítico literario y filósofo - aunque sin decirlo explícitamente-, Crescenciano Grave nos entrega en Walter Benjamin. Una constelación crítica de la modernidad, a lo largo de seis capítulos y poco más de doscientas páginas, la confección de un entretejimiento de algunos de los temas, motivos, pretextos, paseos intertextuales más apasionantes del pensamiento crítico de Benjamin. Atravesando los conceptos de aura, iluminación profana, imagen dialéctica de la historia o la politización del arte, la prosa de Grave se muestra penetrante y audaz; desmenuza los puntos de entrecruce teóricos del Benjamin que hoy en día desearíamos tener: uno de cuyos textos nos hablen al oído, que nos devuelvan la mirada desde cada entresijo en que nos sumergimos en su lectura; porque quien habla en el acto de la recepción de la lectura, no es el autor 
de carne y hueso - o no solamente-; es, mejor dicho, el texto mismo el que nos interpela desde un pasado que en realidad funciona para nosotros retrospectivamente como una prognosis de nuestro presente; no por nada una de las citas más famosas que Benjamin extrae de sus fuentes - del historiador francés decimonónico Michelet-, dice: "cada época sueña la siguiente". Y ello es lo que logra evocar Grave en esta constelación crítica que avista desde un ojo avezado entre los ramajes que hay que sortear de los caminos y veredas trazados por el pensamiento benjaminiano, cuyo esfuerzo data desde hace ya años, y que constituye una de las voces de la crítica en castellano sobre el berlinés. Este hecho se comprueba en La luz de la tristeza (Grave, 2015), otro referente de relevancia para entender a Benjamin en nuestro idioma, del mismo autor. Todo ello sin perder rigor conceptual, ofreciendo a un tiempo destellos de prosa literario-filosófica de difícil, aunque deslumbrante complexión.

En la primera parada de su recorrido, titulada "La iluminación profana", Grave se detiene en esa experiencia extático-profana de que Benjamin habla en su texto Der Surrealismus. Die letzte Momentaufnahme der europäischen Intelligenz (El surrealismo. La última instantánea de los intelectuales europeos), artículo publicado en Die Literarische Welt en 1927, cuyo nombre 1leva marcado en la frente su motivo principal: ituminación profana. En ese texto, el berlinés califica de iluminaciones profanas al paseo, la espera, la lectura o la escritura, y propone como su prototipo de referencia más cercano a la experiencia embriagadora de las drogas o del vino, pero cuyo esfuerzo se concentra en superar (en el sentido de la Aufhebung hegeliana), llevándola al límite de su propia significación. Según Grave, leer y escribir "son formas de la embriaguez en las que uno se encuentra fuera de sí; un arrobamiento cuya experiencia no tolera fácilmente que se le despoje de las sombras que el viejo término de creación ha dejado en él" (Grave, 2019: 16). Este tipo de iluminaciones - experiencias extáticas par excellence - son profanas no tanto porque lo divino deje de operar en ellas; todo consiste en entender, por el contrario, que lo divino opera profanamente a través de ellas en el decurso de la vida cotidiana. Ésta, la vida de todos los días, contiene articuladas, pues, el tipo de experiencias que son la lectura y la escritura, las cuales, al maniobrar "el viejo término de creación", quiebran o entreabren puntos de fuga a través de los cuales se despide un dejo que se respira desde la lejanía de una otra-vida, una en la cual el aprovechamiento de la creación nos sirve a modo de consolatio, al estilo, por ejemplo, de Boecio. 
La imagen del mundo como un libro convoca a su lectura melancólica, y en su habitáculo anida la sapiencia sobre su propia fragilidad. Y justo esta sapiencia permite que el discurso del lector-escritor, dice Grave, "adentrándose en el mundo que se le da a leer, [termine] convirtiendo el cultivo de su arrogancia en cosecha de soledad y amargura" (Grave, 2019: 17). Benjamin no se deja hundir por completo, empero, en las pantanosas aguas de su soledad y su amargura, pues "desplegó su posición aunando las tendencias literaria y política para resistir y combatir el fascismo" (Grave, 2019: 17). Su compromiso, de acuerdo con Grave, depende de lo que el berlinés sostuvo en su conferencia nunca pronunciada Der Autor als Produzent (El autor como productor): que toda tendencia política correcta lo es por el hecho de contener una determinada tendencia literaria. De tal manera que la conjunción de la tendencia política y la literaria es fundamental para entender la situación de Benjamin como escritor. Lo importante de esta contraposición entre pensamiento y vida (tendencia literaria y tendencia política, respectivamente) es ese proceso en que Benjamin se inspira, y que retoma de Pierre Naville: la organización del pesimismo. Esa situación del mundo en que se halla el crítico, el cual, para Grave, se encuentra "atravesado por la catástrofe", no sólo apunta a la concordancia con ese estado de cosas desde el pesimismo, sino que, desde esa misma organización, se avistan destellos que alumbran el cielo de lo que podría ser una respuesta, aunque provisional, ante esa catástrofe, y la clave para vivir una vida (un poco) menos infeliz.

Motivo con el cual tenemos la ocasión de hablar del siguiente apartado del texto, "El lenguaje de la catástrofe", cuya directriz es en su primera parte la distinción entre el lenguaje puro y el lenguaje contenido en las lenguas particulares y atravesada por el papel que Baudelaire desempeña en el pensamiento benjaminiano. Uno de los motivos más fecundos de este apartado consiste en desenrollar la madeja cuyos hilos son la vida y la historia bajo el entendido de la función que la poesía desempeña en esta distinción. Y es que "vida e historia se reúnen en la obra haciendo de ella un ente dinámico por su potencia capaz de sobrevivir a su época y a su autor" (Grave, 2019: 31). Se trata de alguna manera de lo que la crítica francesa literaria de la segunda mitad del siglo xx denominó "la muerte del autor", si por este acontecimiento entendemos el proceso mediante el cual las obras literarias, poéticas y hasta filosóficas dejan de entenderse por una referencia indispensable al autor de carne y hueso, y se comienza a descifrar la dupla vida/historia apelando a la posibilidad del texto mismo de seguir refiriendo a pesar de los 
vericuetos que aquejaron al autor en su tiempo. Si la poesía de Baudelaire o la prosa de Poe pueden seguirnos hablando al oído hasta el día de hoy es por esa cualidad de las composiciones poéticas - y no menos de las filosóficas o las literarias - de trascender la época que las vio nacer. Si por algo se distinguió la poesía de Baudelaire fue por evocar no sólo el París que se le esfumaba ante los ojos y que se le volvía alegoría; también sus versos sirvieron, y ése es un acierto que Grave rescata en su libro, como prognosis de la catástrofe que se avecinaba en nuestro tiempo. Algo de vidente y de profeta encarna en la figura del poeta maldito.

Lo decisivo de esta visión de la vida en el decurso de la historia reside en la distinción que apela a los extremos en que juegan el lenguaje puro y los lenguajes particulares, pues si la poesía puede referir con independencia del sitio histórico que la vio nacer, es porque en ella se manifiesta el principio que Benjamin le concede al lenguaje puro, que funciona como "el núcleo esencial de todas las lenguas" (Grave, 2019: 32). Este núcleo permite que todas las opciones combinatorias de las distintas lenguas puedan quedar referidas a él, sin agotar no obstante la totalidad de significación del lenguaje puro. Si ocurriera este agotamiento, ello coimplicaría ipso facto que el lenguaje puro se redujera a una lengua en específico; mas lo que su principio declara es que éste funja como un suelo sobre el que los distintos lenguajes y sus múltiples combinaciones se den. Por eso es que, recordando a la cita con que Benjamin abre uno de sus textos sobre Baudelaire, el ser humano no necesita en absoluto una capital; ya que lo que nos enseña la dinámica del lenguaje puro es la (casi) anulación del sitio geográfico e histórico que ve nacer una lengua. Así, tenemos que pensar a fortiori que ni París ni Berlín nos dan la respuesta definitiva ante la catástrofe en que desde antaño vivimos, sino que son tan sólo posibles puntos de referencia que nos atañen como humanidad y no como habitantes de determinadas coordenadas geográficas circunstanciales. La dinámica del lenguaje puro nos enseña a pensar desde el punto de vista de la totalidad y no desde nuestra situación peculiar; no porque sea irrelevante: más bien hay que abalanzarnos a respirar el leve aire mesiánico que nos atañe a todas las generaciones presentes respecto de las pasadas.

Hablando de esta transustancialidad que define al arte poético por formar parte del lenguaje puro, se propicia el momento de hablar de la tercera estación del recorrido, en donde Grave nos ofrece en el inicio una imagen panorámica que nos permite entender la concepción benjaminiana de "la decadencia del aura" en el arte moderno. El meollo del asunto está en entender 
cómo confrontarse con los frutos que la tradición nos ofrece: entre una "actitud retrógrada" (Grave, 2019: 57), que despoja el elemento vivo del proceso de recepción y delega al ámbito de lo intocable a los frutos mencionados. También hay otro frente desde el cual esos frutos se aprovechan, incluyendo los cambios radicales que dentro de la misma tradición se encuentran, de manera que lo vivo, lo mutable, queda incluido en dicha recepción, aun sin cesar de respetar la autoridad que mienta la tradición. La segunda es a la que pertenece la significación que Benjamin le concede al concepto de aura. Como es sabido, las nuevas manifestaciones de reproductibilidad técnica que introducen un discontinuum sustancial en la historia del arte son el cine y la fotografía, los cuales "suponen tanto un momento de peligro como una oportunidad revolucionaria" (Grave, 2019: 59). Pero el debate importante se cifra desde la posibilidad que tienen las clases dominantes para apropiarse de las nuevas posibilidades que la técnica ofrece; la apuesta de Benjamin es por que éstas se apropien desde el lado de "los siempre vencidos". Y si con el desarro1lo técnico de la fotografía y del cine se da por primera vez la oportunidad de acercar el arte a éstos, ello debería de implicar por necesidad que la destrucción del aura - ese airecillo que proviene desde una lejanía, por muy cercana que ésta pueda parecer - es el leitmotiv de la puesta en marcha de la apropiación del arte por el ala de los relegados de la marcha triunfal de la historia. El hecho de que el cine y la fotografía acerquen, en sentido literal, el arte a las clases dominadas corre el riesgo, no obstante, de que esas posibilidades técnicas que lo nuevo ofrece se utilicen para amodorrar la conciencia de las clases mentadas mediante métodos nefastos que, de hecho, comenzaría a aplicar cada vez más la entonces naciente industria cultural, que Adorno y Horkheimer se encargaron de analizar críticamente. El punto es que el nuevo arte sea arrebatado de las manos de los siempre vencedores. Chaplin, uno de los modelos prototípicos de Benjamin, es una prueba de que eso es posible.

Hay que actuar, sin embargo, con un poco de más cautela a la hora de dictaminar el acta de defunción del proceso aurático, pues otro aspecto lamentable de lo que deja a su paso, la destrucción del aura, es la lamentable pérdida de una experiencia del arte en la que "la obra se apodere de nuestros pensamientos" (Grave, 2019: 79). En última instancia, la pérdida es de una experiencia de arrobamiento en que la obra es la que nos devuelve la mirada, y la que nos habla al oído. Dejarnos asaltar por la obra de arte, desarropados, sin otro fin que el de complacernos en nuestra propia mismidad, es algo que 
hace tanta falta en nuestra actualidad, en la que la utilización que el capital hace de las masas imprime su sello, sordo, ante la realidad que transcurre ante sí. La invitación sería a dejarnos llevar por el remanso de nuestra tranquilidad ante la situación de miseria y podredumbre que nos aqueja día con día. La sensatez teórica respecto de la destrucción del aura consistiría más en atestiguar su decadencia que en posicionarse meramente a favor o en contra, ya que el decurso de esta decadencia es un camino sinuoso.

Y la misma sensatez que se requiere a la hora de dictaminar la defunción del aura es la que atraviesa todo el texto de Grave, que nos entrega, como dijimos, claves para afrontar la vida de todos los días. La invitación es a propiciar una cotidianidad en la que el valor de cambio cese de acaparar todos y cada uno de los recovecos del globo terráqueo, y que una sutil dialéctica de la mirada nos enseñe a entresacar las miradas de esos mil y un focos de una experiencia que aún asfixiada y empobrecida por la especialización que demanda el capital financiero a los individuos de la sociedad, pueda ofrecernos una vida un poco más vivible. Ello es lo que nos ofrece el texto reseñado.

\section{Referencia bibliográfica}

GRAVE, Crescenciano. (2015). La luz de la tristeza. Ensayos sobre Walter Benjamin. Edén Subvertido. 